\title{
INCIDENCIA DE POSIBLES BACTERIAS CAUSANTES DE MASTITIS EN LOS MUNICIPIOS DE PAMPLONA, PAMPLONITA Y TOLEDO, NORTE DE SANTANDER
}

\section{INCIDENCE OF POSSIBLE BACTERIA CAUSING MASTITIS IN THE MUNICIPALITIES OF PAMPLONA, PAMPLONITA AND TOLEDO, NORTE DE SANTANDER}

\author{
*Maldonado, Natalie'1, Ortiz, Jesús D., Rojas C. Liliana', Cajiao, Angela', Capacho, \\ Alfonso, Bermúdez, Jessica²
}

Universidad de Pamplona, Facultad de Ciencias Básicas, 1 Grupo de Investigación en Microbiología y Biotecnología (GIMBIO); 2 Semillero de Microbiología y Biotecnología (SIMBIO). Km. 1 Vía Bucaramanga, Pamplona Norte de Santander-

Colombia

Recibido 21 de Octubre 2015; aceptado 30 de Marzo de 2016

\section{RESUMEN}

La mastitis bovina es la inflamación de la glándula mamaria y su causa se debe al efecto combinado de factores, especialmente a la invasión de patógenos a través del canal del pezón. Ésta enfermedad ocasiona pérdidas a la industria láctea, disminuye la producción individual y la calidad higiénica de la leche. A partir de muestras de leche se aislaron e identificaron posibles especies de Estafilococos y Enterobacterias y sus incidencias en los municipios de Toledo, Pamplona y Pamplonita en Norte de Santander. Se analizaron 163 muestras que se inocularon por agotamiento en medios 
*Autor a quien debe dirigirse la correspondencia. Maldonado, Natalie Email: nataliemaldonado37@gmail.com de cultivo Agar Sangre y Agar EMB y se incubaron a $37^{\circ} \mathrm{C}$ por 24 horas. La identificación preliminar de las bacterias se realizó a través de pruebas bioquímicas convencionales. Un total de 105 bacterias fueron aisladas; 95 aislamientos correspondieron a: Staphylococcus aureus, S. capitis, S. epidermidis, S. haemolyticus, S. saprophyticus, S. simulans y S. xylosus, y 10 aislamientos a: Escherichia coli, Enterobacter agglomerans, Klebsiella pneumoniae, Shigella spp. y Acinetobacter calcoaceticus. Staphylococcus epidermidis mostró la mayor incidencia para Pamplona, Pamplonita y Toledo con $22 \%, 31.3 \%$ y $7.40 \%$, respectivamente. En Pamplona, la incidencia para Acinetobacter calcoaceticus y Shigella spp. fue $2 \%$; en Pamplonita se aisló Klebsiella pneumoniae y Shigella spp. (3.1\%) y en Toledo E. coli y Enterobacter agglomerans (3.7\%). Las especies aisladas en este estudio han sido descritas como causantes de mastitis en el ganado lechero y su presencia se relaciona con las condiciones de limpieza y las prácticas de ordeño.

Palabras clave: bacterias, incidencia, leche, mastitis bovina.

\section{ABSTRACT}

Bovine mastitis is the inflammation of the mammary gland and is due to a combination of factors, especially the invasion of pathogens through the teat canal. This disease causes losses to the dairy industry, individual production decreases and the hygienic quality of milk. From milk samples they were isolated and identified possible Staphylococci and Enterobacteriaceae species and their incidence on the municipalities of Toledo, Pamplona and Pamplonita in Norte de Santander. 163 samples were inoculated by streaking technique in culture media blood agar and EMB agar and incubated at $37^{\circ} \mathrm{C}$ for 24 hours were analyzed. Preliminary identification of bacteria 
was performed using conventional biochemical tests. A total of 105 bacteria were isolated; 95 isolates corresponded to: Staphylococcus aureus, S. capitis, S. epidermidis, S. haemolyticus, S. saprophyticus, S. simulans and S. xylosus, and 10 isolates: Escherichia coli, Enterobacter agglomerans, Klebsiella pneumonia, Shigella spp. and Acinetobacter calcoaceticus. Staphylococcus epidermidis showed the highest incidence to Pamplona, Pamplonita and Toledo with $22 \%, 31.3 \%$ and $7.40 \%$, respectively. In Pamplona the incidence for Shigella spp. and Acinetobacter calcoaceticus was $2 \%$; in Pamplonita Klebsiella pneumonia and Shigella spp. was isolated (3.1\%) and in Toledo E. coli and Enterobacter agglomerans (3.7\%). The species isolated in this research have been reported to cause mastitis in dairy cattle and its presence is related to the cleanliness and milking practices.

Keywords: bacteria, incidence, milk, bovine mastitis.

\section{INTRODUCCIÓN}

La mastitis bovina se caracteriza por la inflamación de la glándula mamaria y los tejidos secretores, la cual resulta de una infección causada por patógenos que penetran a la glándula a través del canal del pezón (Bradley, 2002). Se clasifica de acuerdo con los criterios de manifestación clínica y duración: en términos de los signos o manifestaciones se divide en clínica y subclínica, mientras que según la duración puede ser subaguda, aguda, super aguda y crónica (Philpot y Nickerson, 2001).

La diversidad de los agentes microbianos involucrados en la enfermedad es alta; un promedio de 137 especies se han aislado de la glándula mamaria bovina (Morales, 2011).

Las bacterias pueden ser patógenos mayores de la glándula mamaria como Staphylococcus aureus, Streptococcus agalactiae y Actinomyces pyogenes las 
cuales son contagiosas; otras bacterias ambientales como Streptococcus dysgalactiae y Streptococcus uberis, y otras coliformes como Escherichia coli, Klebsiella spp. y Enterobacter spp. (Saran y Chaf fer, 2000).

La mastitis bovina es de gran importancia debido a las grandes pérdidas económicas que produce (reduce la producción entre un 10 y $12 \%$ en un cuarto afectado durante la lactancia) (Alfonso et al., 2008); además por los efectos sobre la calidad de la leche al reducirse componentes como la caseína, grasas, sólidos totales y calcio (Herrera, 2015). También aumenta el contenido de sodio y cloro así como la carga microbiana, produciendo un aumento en el recuento de células somáticas (Insua et al., 2008; Calderón et al., 2011).

A nivel sanitario la mastitis bovina es importante debido a que microorganismos causantes como Estafilococos y Enterobacterias pueden producir toxinas que provocan enfermedades a los seres humanos

como

endocarditis, meningoencefalitis, enteritis y artritis, lo que representa un riesgo para el ser humano (Insua et al., 2008).

En general, se ha sugerido que los métodos de control y prevención deben ser prácticos, efectivos, de bajo costo económico y con capacidad de disminuir nuevas infecciones (Philpot y Nickerson, 1993). Estos deben incluir condiciones de limpieza en los alojamientos y excelente uso de higiene durante el ordeño, entre otros.

En municipios lecheros de Norte de Santander se desconoce sobre los posibles microorganismos causantes de mastitis bovina y su incidencia. Por esta razón, en este estudio se planteó el aislamiento de las posibles bacterias (Estafilococos y Enterobacterias) causantes de mastitis y se evaluó la incidencia de los microorganismos aislados de muestras de leches en hatos lecheros de los municipios de Toledo, Pamplona y Pamplonita en Norte de Santander.

\section{MATERIALES Y MÉTODOS}

\section{Área de estudio}

Las muestras de leche colectadas para este estudio, se tomaron de diferentes hatos lecheros ubicados en los municipios de:
Pamplona, Pamplonita y Toledo, Norte de Santander, Colombia.

Toma de muestras de leche y Prueba de California para Mastitis (CMT) 
En este estudio se recolectaron y analizaron 163 muestras de leche de cuartos individuales provenientes de los distintos hatos lecheros de los municipios de estudio.

A cada muestra colectada se le aplicó el Test de California para Mastitis (CMT). Las muestras se almacenaron en frascos de vidrio estéril y se transportaron bajo condiciones de refrigeración, al laboratorio de Microbiología de la Universidad de Pamplona.

\section{Aislamientos de posibles Estafilococos y Enterobacterias}

De cada una de las muestras de leche colectadas se tomó una asada, la cual se inoculó por agotamiento en Agar Sangre para Estafilococos y en Agar Eosina Azul de Metileno (EMB) para Enterobacterias.

Una vez sembradas las muestras se procedió a incubarlas a $37^{\circ} \mathrm{C}$ por 24 horas. Pasado el tiempo de incubación, se realizó un repique a Agar Nutritivo de las distintas morfologías encontradas en los dos medios de cultivo para su posterior identificación.

La caracterización preliminar de las bacterias aisladas se llevó a cabo mediante pruebas bioquímicas. Las pruebas bioquímicas para Estafilococos incluyeron: Nitrato, Arginina, Urea, Maltosa, Trehalosa, Xilosa, Celobiosa, Sacarosa, Manosa, Rafinosa, hemólisis, Catalasa, y Coagulasa de acuerdo al perfil propuesto por Koneman (1992).

Las pruebas bioquímicas para Enterobacterias incluyeron: Triptófano, RM/VP, Citrato, Lisina, Arginina, Ornitina, Adonitol, Sorbitol, Manitol, Celobiosa, Lactosa, Xilosa, Glucosa, Malonto, SIM, Arabinosa, Rafinosa, Ramnosa, Sacarosa, Fenillalanina y Catalasa (Koneman, 1992).

Una vez identificadas las posibles bacterias se conservaron en medio de cultivo $\mathrm{BHI}$ con glicerol al $30 \%$, almacenándolas en el freezer a una temperatura de $-40^{\circ} \mathrm{C}$.

\section{RESULTADOS Y DISCUSIÓN}

Se obtuvo un total de 95 aislamientos de Estafilococos y 10 aislamientos de Enterobacterias en los municipios muestreados (Tabla 1). 
@-LIMENTECH CIENCIA Y TECNOLOGÍA ALIMENTARIA ISSN 1692-7125. Volumen 14 No. 1, p. 17 - 26, año 2016 Facultad de Ingenierías y Arquitectura Universidad de Pamplona

Tabla 1. Número de aislamientos de Estafilococos y Enterobacterias en los municipios muestreados.

\begin{tabular}{|c|c|c|c|}
\hline Municipio & $\begin{array}{c}\text { No } \\
\text { muestra }\end{array}$ & $\begin{array}{c}\text { Estafilo } \\
\text { cocos }\end{array}$ & Enterobacterias \\
\hline Pamplona & 50 & 29 & 2 \\
\hline Pamplonita & 32 & 34 & 2 \\
\hline Toledo & 81 & 32 & 6 \\
\hline Total & $\mathbf{1 6 3}$ & $\mathbf{9 5}$ & $\mathbf{1 0}$ \\
\hline
\end{tabular}

En todos los municipios objeto de estudio se aislaron e identificaron de acuerdo con los resultados de las pruebas bioquímicas las siguientes posibles especies de Estafilococos (Figura 1): Staphylococcus aureus coagulasa positivo, $S$. epidermidis, $S$. simulans, S. capitis, S. saprophyticus, $S$. xylosus, S. haemolyticus y $S$. cohnii y de Enterobacterias: Shigella spp., Acinetobacter calcoaceticus, Klebsiella pneumoniae, Escherichia coli y Enterobacter agglomerans.

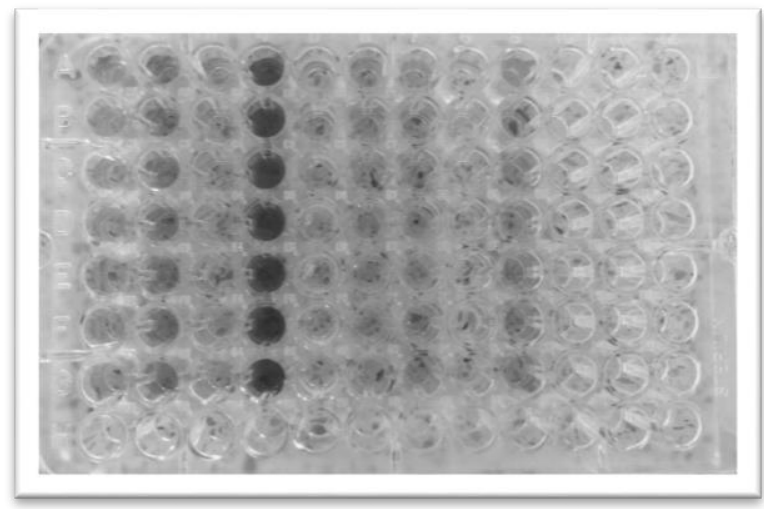

Figura 1. Pruebas bioquímicas para Estafilococos.
En la Figura 2 se observa la morfología macroscópica y microscópica de un Estafilococo manitol positivo.
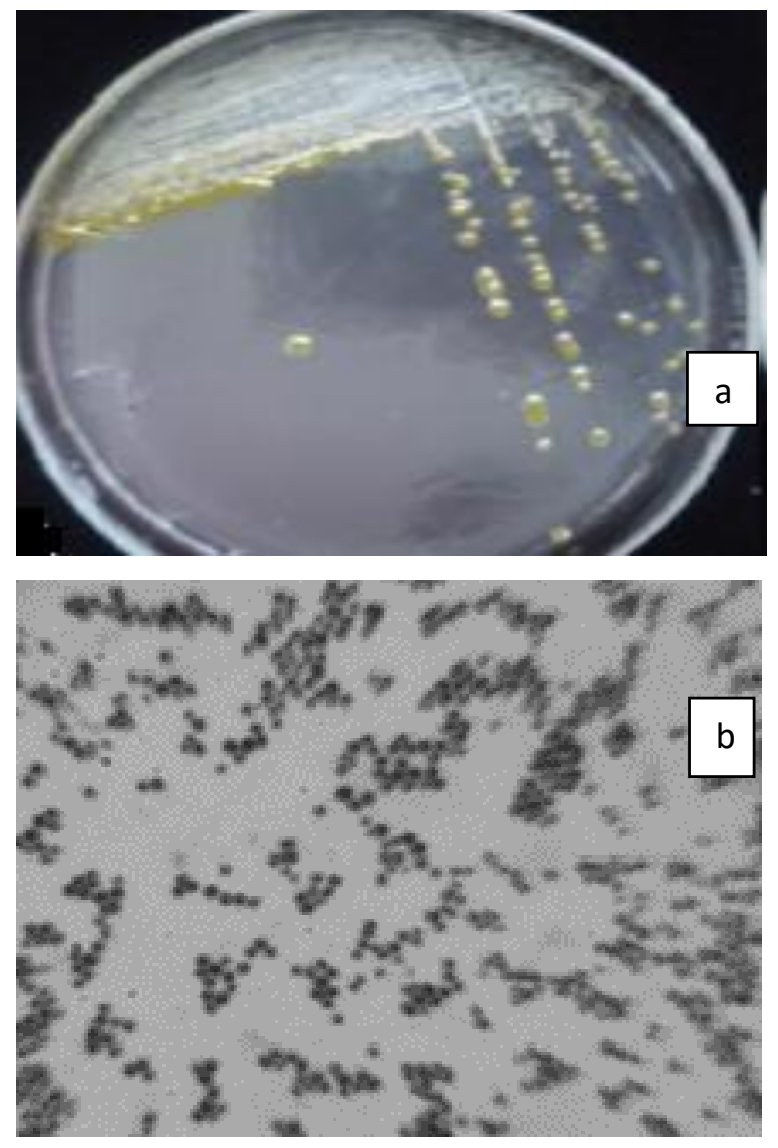

Figura 2. (a). Descripción macroscópica y (b) microscópica de un microorganismo del género Staphylococcus spp. manitol positivo. Objetivo: 100X. 
La incidencia de Estafilococos por especie y municipio se muestra en la Figura 3. De los aislamientos obtenidos en Pamplona, Pamplonita y Toledo, la mayor incidencia se presentó para Staphylococcus epidermidis con $22 \%, 31.3 \%$ y $7.40 \%$, respectivamente. En este estudio la incidencia de Staphylococcus aureus coagulasa positivo fue $18.75 \%$ en el municipio de Pamplonita, en Toledo $7.40 \%$ y en Pamplona la incidencia fue $4 \%$. Staphylococcus aureus coagulasa positivo ha sido considerado como un patógeno mayor de la glándula mamaria predominante en la mastitis bovina (Calderón y Rodríguez, 2008; Calderón et al., 2011). En los municipios de Pamplonita y Toledo esta especie presentó una incidencia alta, contrario a lo encontrado en Pamplona. Esto puede deberse a las prácticas de ordeño efectuadas en cada hato lechero, ya que los contagios producidos por $S$. aureus se producen principalmente durante el ordeño (Blowey y Edmondson, 1995).

Las especies S. simulans, S. xylosus, $S$. saprophyticus presentaron incidencias intermedias para los tres municipios.

Las especies de Estafilococos S. simulans, S. xylosus, S. saprophyticus han sido descritas como bacterias causantes de mastitis bovina y son consideradas de gran importancia debido a su carácter contagioso.

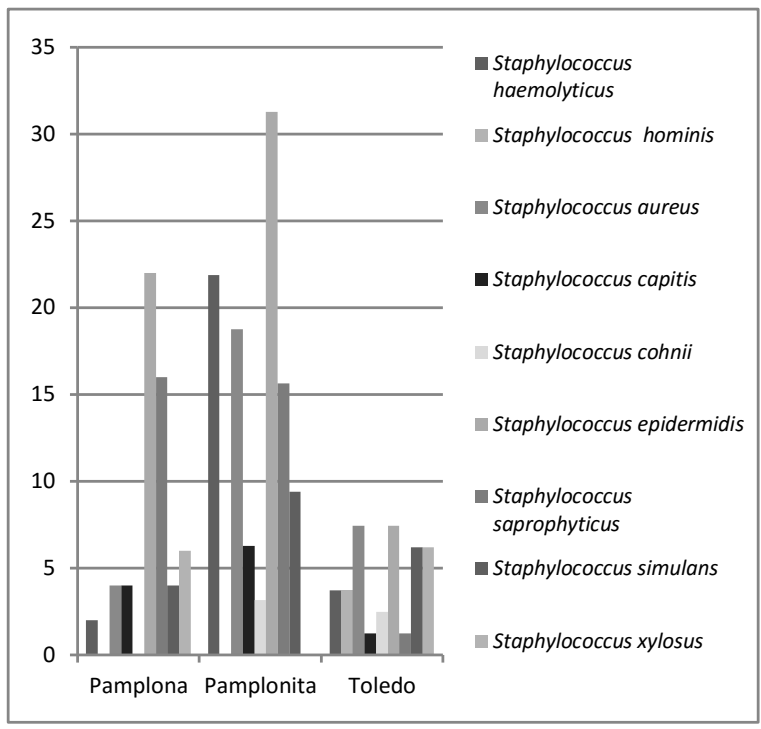

Figura 3. Incidencia de Estafilococos por especie y municipio.

En los tres municipios estudiados se presenta una alta incidencia de $S$. epidermidis, es una bacteria oportunista causante de mastitis contagiosa la cual se aloja en la ubre de la vaca y los pezones (Saran y Chaf fer, 2000).

La incidencia de Enterobacterias se presenta en la Figura 4. En el municipio de Pamplona se aislaron las especies Acinetobacter calcoaceticus y Shigella spp.; bacterias que presentaron una incidencia de $2 \%$. En Pamplonita se aislaron las posibles especies Klebsiella pneumoniae y Shigella spp., con una incidencia de $3.1 \%$; finalmente, para Toledo se aislaron las posibles especies $E$. coli y Enterobacter agglomerans con una incidencia de $3.7 \%$ La morfología 
macroscópica y microscópica se presenta en la Figura 5.

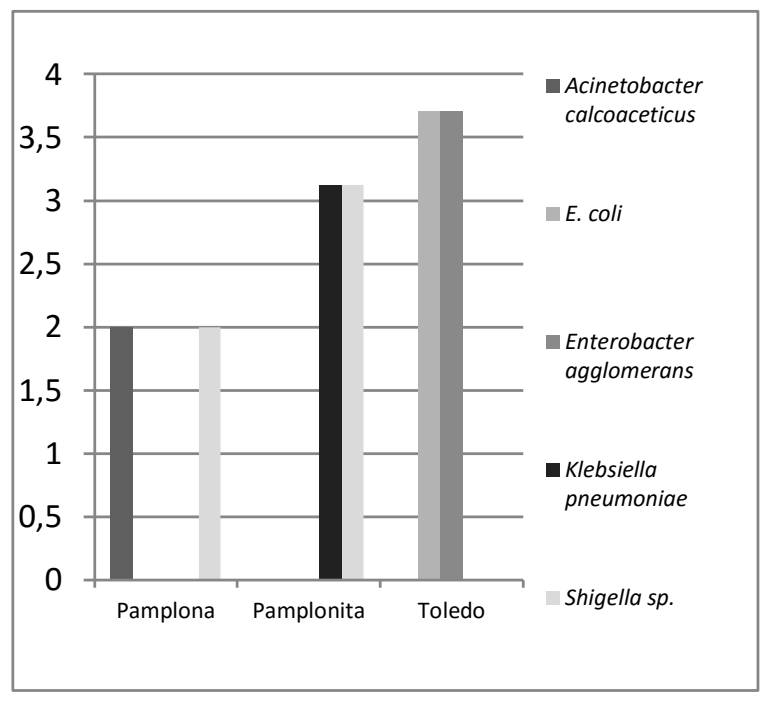

Figura 4. Incidencia de Enterobacterias por especie y municipio.

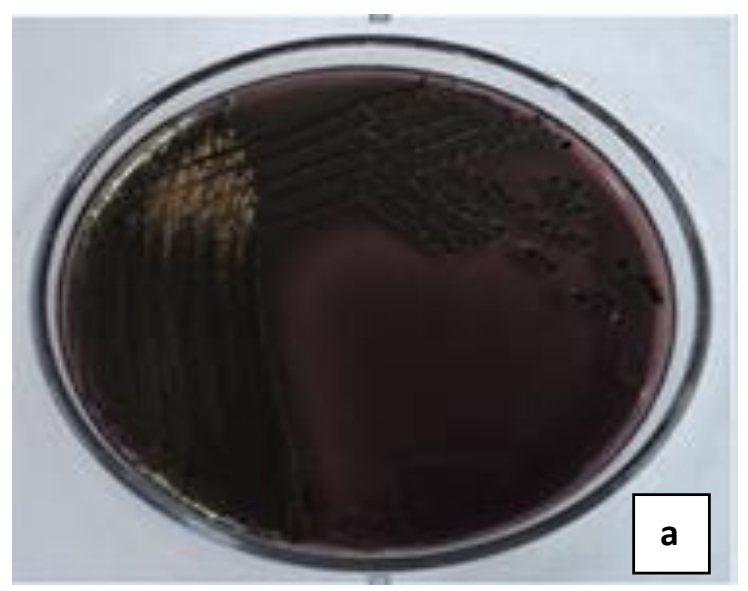



Figura 5. (a) Descripción macroscópica y (b) microscópica de una Enterobacteria (posible E. coll). Objetivo: 100X.

Las Enterobacterias aisladas de las muestras de leche se deben principalmente a las condiciones higiénicas de los sitios de ordeño, camas y comederos de los animales, ya que los coliformes se encuentran en el suelo, tracto digestivo de los animales y en el estiércol. E. coli es el primer microorganismo asociado con la producción de mastitis bovina, y se incluye dentro de los microorganismos de contaminación ambiental debido a los pisos sucios y al estiércol (Alfonso et al., 2008). 


\section{CONCLUSIONES}

Las especies identificadas en este estudio han sido reconocidas previamente como posibles agentes microbianos asociados con mastitis bovina, lo cual corrobora la información obtenida en otros estudios.

Los aislamientos de Estafilococos y Enterobacterias obtenidos en este estudio como posibles bacterias causantes de mastitis bovina, corresponden a microorganismos ambientales y contagiosos, además se asocian con las prácticas de higiene entre y durante los ordeños.

La incidencia de E. coliencontrada en Toledo y de Shigella spp. en Pamplonita, además de las observaciones realizadas en los sitios, nos deja concluir que las bajas condiciones de limpieza en los lugares de ordeño son las causantes de lo hallado.

Los resultados previos obtenidos en este estudio sugieren de un lado un problema de salud animal y su efecto potencial para la salud del hombre, y de otro lado una posible disminución de la productividad económica. Esto último como consecuencia de la baja calidad de la leche y disminución en la producción, aspectos relacionados con la mastitis bovina de tipo subclínica.

Bradley, RADLEY, A. (2002). Bovine mastitis: an evolving disease. Vet J. 164: 116- 128.

Calderón, A. y Rodríguez, V. (2008). Prevalencia de mastitis bovina y su etiología infecciosa en sistemas especializados en producción de leche en el Altiplano Cundiboyacense (Colombia). En: Revista Colombiana de Ciencias Pecuarias. Vol.; 21, p. 583-584. 
Calderón, A., Rodríguez, V., Arrieta, G. y Máttar, S. (2011). Prevalencia de mastitis bovina en sistemas doble propósitos en Montería (Colombia): etiología y susceptibilidad antibacteriana. Revista Colombiana de Ciencias Pecuarias. 24: 19-28.

Herrera, F.A. Santos, J. B., Perfiles De PcrRflp En Staphylococcus Aureus Meticilina-Resistentes Aislados A Partir De Queso Fresco Artesanal. (2015). @limentech, Ciencia y Tecnología Alimentaria. Vol 13 N². P. $145-153$.

Insua, D. A., Pérez, C. y Silveira, E. (2008). Evaluación epizootiológica de la mastitis

Saran, A., y Chaf fer, M. (2000). Mastitis y calidad de leche. Editorial Intermédica. Buenos Aires, Argentina. 194 p. bovina en cuatro vaquerías. Revista Electrónica de Veterinaria. 9 (7): 1-9.

Koneman, E.; Allen, S.; Dowell, V.R.; Janda, W.; Sommers, H. y Winn, W. (1992). Diagnóstico microbiológico. Tercera edición. Argentina: Editorial Medica Panamericana.

Morales, I. H. (2011). Mastitis bovina: enfoque biotecnológico. Cali: Reciteia. $p$. 217-218.

Philpot, N. y Nickerson, S. (2001). Ganando la lucha contra la mastitis. Naperville, USA. $192 \mathrm{p}$. 